\title{
Technical Guide
}

National Cancer Institute

\section{Source}

National Cancer Institute. Technical Guide. NCI Thesaurus. Code C81929.

A document that provides basic information or instruction related to performing a specialized skill or task. 